Article

\title{
Vibrational Spectroscopy of Adsorbed Sulfate and Nitrate Ions on Au(100) Electrodes
}

\author{
Inês. R. Moraes, Maria Cecilia P.M. da Cunha and Francisco C. Nart \\ Instituto de Química de São Carlos, Universidade de São Paulo, C.P. 780, \\ 13560-970 São Carlos - SP, Brazil
}

Dedicated to Prof. Osvaldo Sala on the occasion of his $70^{\text {th }}$ birthday

and in recognition of his contribution to vibrational spectroscopy

Received: July 21, 1996

Neste trabalho os aspectos de íons sulfato, sulfato ácido e nitrato adsorvidos em eletrodos de $\mathrm{Au}(100)$ são apresentados. Foi encontrado que os íons sulfato apresentam somente uma banda dependente do potencial localizado entre $1150-1220 \mathrm{~cm}^{-1}$, a qual tem sido atribuida à vibração simétrica de uma estrutura com simetria $\mathrm{C}_{2 \mathrm{v}}$ ou $\mathrm{C}_{3 \mathrm{v}}$, devido à adsorção através de um ou dois átomos de oxigênio. O sulfato ácido encontra-se parcialmente deprotonado quando adsorvido. A perda de próton é função do potencial aplicado. Para potenciais mais positivos aumenta a perda de prótons. A banda para o sultato adsorvido está localizada entre $1080 \mathrm{e} 1090 \mathrm{~cm}^{-1}$. Os íons nitrato são adsorvidos sob uma dupla coordenação ao eletrodo de $\mathrm{Au}(100) \mathrm{c}$ as bandas espectrais são localizadas em $1020 \mathrm{~cm}^{-1}$ (fraca) e $1450 \mathrm{~cm}^{-1}$.

The vibrational spectra of adsorbed sulfate, bisulfate and nitrate ions on $\mathrm{Au}(100)$ electrodes are reported. It is found that sulfate ions present only one detectable potential dependent band located between $1150-1220 \mathrm{~cm}^{-1}$, which has been assigned to the symmetric vibration of a $\mathrm{C}_{2} \mathrm{v}$ or $\mathrm{C}_{3} \mathrm{v}$ symmetry, due to the adsorption through one of two oxygen atoms. Bisulfates are partially deprotonated when adsorbed. The proton loss is a function of the applied electrode potential. For more positive potentials the proton loss increases. The band for adsorbed bisulfate ions is located at $1080-1090 \mathrm{~cm}^{-1}$. Nitrate ions are doubly coordinated to the $\mathrm{Au}(100)$ surface and the spectral bands are located at $1020 \mathrm{~cm}^{-1}$ (weak) and $1450 \mathrm{~cm}^{-1}$.

Keywords: ion adsorption, electrochemical in situ FTIR

\section{Introduction}

For a long time, vibrational spectroscopy has been largely used in surface science both to study the interaction of surfaces with adsorbed molecules and to identify surface reaction intermediates and products. The extensive literature data and discussions of vibrational spectroscopy applied to surface science have been surveyed in different comprehensive reviews ${ }^{1,2}$.

The use of vibrational spectroscopy as an analytical technique in surface science is based on the well-documented fact that the vibrational properties of adsorbed molecules are sensitive to the interaction of the molecule with the surface, and to the surface local environment as well ${ }^{1-3}$. Band position, intensity and band shape have been used to characterize different types of interaction between adsorbed molecules at surfaces and with surfaces ${ }^{1-3}$.

Although very appropriate at clean surfaces under vacuum, vibrational spectroscopy has not been useful to study surfaces under electrochemical environments due to the presence of liquid electrolytes. The discovery of the SERS effect opened an interesting new field, since Raman scattering of water molecules is sufficiently weak to allow the study of adsorbed molecules at electrochemical interfaces. The problem is that surface enhancement is limited to some metals and rough surfaces, thus hampering the use of SERS 
to study metals of the platinum group, which are in general good catalysts for electrochemical reactions. Attempts to use SERS to study such metals have shown that it is possible when the platinum group metals are deposited on rough gold substrates ${ }^{4}$, but this limits the use of SERS to polycrystalline surfaces.

The use of IR spectroscopy to study electrochemical interfaces becomes feasible with the use of a thin electrolyte layer between the electrode and a transparent window in order to minimize the effect of the solvent water. The pioneering work was conducted by Kunimatsu et al. in $1980^{5}$. At that time, the weak signal of the grating spectrometers required the use of an electrode potential modulation which made it possible through the use of a lock-in amplifier, to obtain an acceptable signal-to-noise ratio. The potential modulation limits the use of IR spectroscopy to reversible reactions and to adsorbed molecules which present potential-induced band shifts, like adsorbed CO.

The use of FT spectrometers gave a new impetus to the study of electrochemical interface by vibrational spectroscopy $^{6}$, since the potential modulations were no longer necessary, so that other reactions and adsorbates can now be studied. The problem remains that the final result is a "differential reflectance" of the electrode surface at two different electrode potentials. This kind of procedure introduces some problems during spectra acquisition, since the migration of solution components out of and into the thin solution layer can affect the spectral results, as has been discussed in detail by several authors ${ }^{7-11}$.

The application of FTIR spectroscopy to study electrochemical interfaces comprises different kind of processes, such as adsorption of ions and neutral molecules, electrochemical reactions, the electrochemical Stark effect, and other interface properties.

The study of the adsorption of ions at the electrochemical interface at well-ordered electrodes by vibrational spectroscopy has recently attracted the attention of several investigators. Vibrational spectroscopy allows the identification of surface processes, which are of fundamental importance to understanding electrochemical electrified interfaces. Particular attention has been given to the adsorbed oxyanions, like sulfate ${ }^{12-18}$, phosphate ${ }^{19-23}$, and nitrate $^{24}$ at platinum and gold electrodes. The oxyanions are commonly used as supporting electrolytes in most electrochemical systems. Therefore, the understanding of oxyanion adsorption is of both fundamental and practical importance in electrochemistry.

The adsorbed sulfate/bisulfate ions at well-ordered electrode surfaces reveals that the chemical interfacial equilibrium $\mathrm{HSO}_{4}{ }^{-} / \mathrm{SO}_{4}{ }^{2-}$, strongly depends on the surface crystallography in the case of platinum electrodes ${ }^{15,16}$. It has been found that at $\mathrm{Pt}(111)$ surfaces, solution bisulfate is readily deprotonated, leading to adsorbed $\mathrm{SO}_{4}{ }^{2-}$ at the polarized electrode surface ${ }^{15}$. More recently it has been proven that bisulfate ions are also deprotonated at $\mathrm{Au}(111)$ upon adsorption ${ }^{18}$. Such processes are not accessible to other electrochemical techniques, thus vibrational spectroscopy allows us to understand the electrochemical interface properties at a molecular level.

The electrochemistry of nitrate ions has attracted the attention of many researchers due to its importance in the application of electrochemical reactions for cleaning in waste water processing. Little spectroscopic information about adsorbed intermediates exists in the literature ${ }^{23}$. More specifically, adsorbed nitrate ions were proposed to be the starting step of nitrate reduction on electrodes ${ }^{24}$. In a previous publication, we suggested that the nitrate ions are adsorbed under a two-fold coordination on polycrystalline gold electrodes ${ }^{23}$. This conclusion was based on the position of the vibrational features allowed by the surface selection rule at values close to those presented by bridge $\mathrm{NO}_{3}{ }^{-}$transition metal complexes. However, one-fold coordination at the surface cannot be discarded due to the polycrystalline nature of the electrode surface. At a more organized electrode surface the adsorption sites are energetically more uniform, thus probably leading to a more specific kind of adsorption, which makes the characterization of the spectral feature of the adsorbed nitrate ions more precise.

In this work we investigate the adsorption of sulfate and nitrate on a $\mathrm{Au}(100)$ single crystal electrode. The study of the adsorbates $\left(\mathrm{SO}_{4}{ }^{2-}\right.$ and $\mathrm{NO}_{3}{ }^{-}$) on a gold single crystal is very important in the context of understanding the physico-chemical properties of well-defined surfaces at electrochemical interfaces. As pointed out above, different acid-base behavior has been observed for different crystalline faces on Pt electrodes, and there is evidence of the behavior of the acid-base equilibrium for sulfate adsorbed on $\mathrm{Au}(111)$ single crystals being different from that of polycrystalline gold electrodes. Thus, the objective of this work is to study the adsorption of sulfate/bisulfate ions and nitrate ions on Au(100) single crystal electrodes to characterize the interfacial properties of this surface, and to try to understand the adsorbate geometry for a tetrahedral, as well as a planar ion on this surface.

\section{Experimental}

A BOMEM DA-8 spectrometer equipped with a $\mathrm{L}-\mathrm{N}_{2}$ cooled MCT detector was used in the in situ experiments. The spectroelectrochemical cell was made of PTFE with a $\mathrm{CaF}_{2}$ transparent flat window placed at the bottom of the cell. A gold ring was used as the auxiliary electrode and a $\mathrm{Pd} / \mathrm{H}_{2}$ clectrode was used as a reference.

All solutions were prepared with Merck Suprapur reagents and Millipore Milli-Q water.

The Au(100) single crystal (99.999\%) was of a cylindrical form with a diameter of $5 \mathrm{~mm}$, and was obtained from Metal Crystal 7 \& Oxides (Cambridge, Great Britain). The 
details for the preparation of the single crystal have been described elsewhere ${ }^{25}$. The final preparation consisted of annealing the Au single crystal in a gas flame for about 2-3 $s$ at $800^{\circ} \mathrm{C}$ and rapidly-quenching it in ultrapure water. The crystal was transferred to the spectroelectrochemical cell protected by a drop of water.

Before each experiment, the electrode was cycled electrochemically in the base electrolyte to control the quality of the crystal surface and the solution.

The procedure to achieve the spectra has already been described in detail in previous publications ${ }^{14}$. The spectra were collected by stepping the potential between a reference and a sample potential every 1000 scans up to approximately 15,000 scans. This number of scans was necessary to take into account the small amount of adsorbed particles at the electrode surface, typically $10^{15}$ particles $/ \mathrm{cm}^{2}$, which corresponds to about $10 \%$ of a monolayer.

The reference potential at $0.05 \mathrm{~V} v s . \mathrm{Pd} / \mathrm{H}_{2}$ was chosen because a negligible adsorption of sulfate and nitrate is expected at this potential. The final spectra were calculated as the ratio between the sample $(R)$ and the reference $\left(R_{0}\right)$ spectra, which results in bands in positive direction due to the loss, and in bands in negative direction due to the gain of species in the optical path at the sample potential.

\section{Results and Discussion}

Characterization of the vibrational features of adsorbed sulfate

In the case of in situ reflectance spectroscopy at electrochemical interfaces, it is difficult to use the surface selection rule to take advantage of light modulation experiments. The differences in reflectivity and in band intensity between the two polarizations does not allow good band compensation, thus resulting in unreliable spectra. However, it is possible to use s- and p- polarization to identify bands arising from adsorbed or dissolved species, and therefore unequivocally assign the spectral features for both kinds of species.

In Fig. 1 two spectra at $\mathrm{E}=1.2 \mathrm{~V}$, recorded with s- and p-polarized light of the adsorbed sulfate on $\mathrm{Au}(100)$ at $\mathrm{pH}$ 2.8 , are shown. As stated above, large differences in intensity for the positive band are observed in both spectra. In the p-polarized light spectrum, positive and negative bands can be easily identified, while in the spectrum with s-polarized light only positive bands are present. The positive band in both spectra is centered at $1100 \mathrm{~cm}^{-1}$, and can be assigned to the $v_{3}$ triply degenerated mode of dissolved $\mathrm{SO}_{4}{ }^{2-}$. The positive character represents the depletion of aqueous $\mathrm{SO}_{4}{ }^{2-}$ from the optical path at the sample potential, caused by the adsorption of sulfate at the electrode surface.

The bands in negative direction centered at about 1190 $\mathrm{cm}^{-1}$ is then easily assigned to the adsorbed $\mathrm{SO}_{4}{ }^{2-}$, as already reported for other electrodes such as polycrystal-
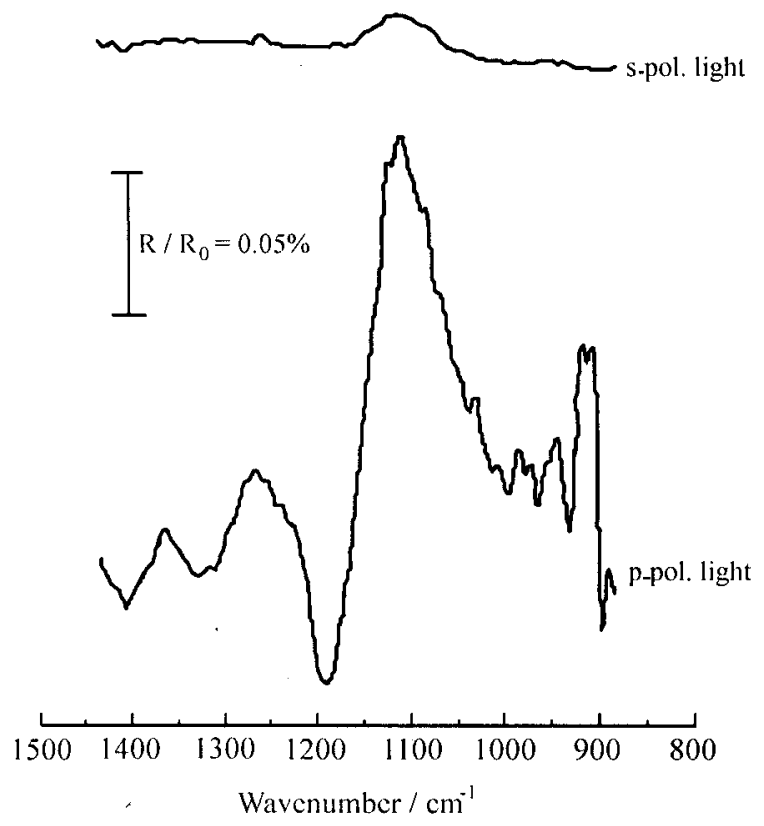

Figure 1. Comparison of in situ IR reflectance spectra obtained with sand p-polarized radiation of sulfate ions on a $\mathrm{Au}(100)$ electrode at 1200 $\mathrm{mV}$ from a solution containing $0.5 \mathrm{M} \mathrm{KF}+0.69 \mathrm{M} \mathrm{HF}+10^{-2} \mathrm{M} \mathrm{Na}_{2} \mathrm{SO}_{4}$ $(\mathrm{pH}=2.8)$. Reference spectrum: $30 \mathrm{mV}$. Res. $8 \mathrm{~cm}^{-1}$.

line platinum ${ }^{12,13}$ and gold $^{17}$, and single crystal $\mathrm{Au}(111)^{18}$. Another band located below $1000 \mathrm{~cm}^{-1}$, due to the activation of the forbidden totally symmetric mode of sulfate, is also expected due to the break up of symmetry of the sulfate ions upon adsorption. Due to the large noise in this region, it is difficult to clearly identify this band. Furthermore, the intensity of this stretching vibration is expected to be very weak. This mode has been observed for the case of adsorbed sulfate ions on polycrystalline gold electrodes ${ }^{17}$.

- As previously discussed for the case of polycrystalline gold $^{17}$, it is very difficult to assign a defined geometry for the adsorbed ion from pure spectroscopic data. Nevertheless, the geometry of the $\mathrm{Au}(100)$ face makes the three-fold adsorption difficult, due to the mismatch between the distance of the gold atoms at the surface and the distance of the oxygen atoms of the sulfate ions. In this case, only twoand one-fold adsorption are expected.

Both two- and one-fold adsorption reduce the symmetry of the adsorbed molecule to a $\mathrm{C}_{2 \mathrm{v}}$ or $\mathrm{C}_{3 \mathrm{v}}$ symmetry, respectively. In both cases, only two stretching modes are allowed, namely the symmetric vibrations represented in Fig. 2. As stressed above, the $v_{1}\left(A_{1}\right)$ may be very weak, due to the small dynamic dipole moment of this vibration. It is therefore clear that the $1190 \mathrm{~cm}^{-1}$ band observed in the p-polarized light of Fig. 1 can be assigned to the stretching vibration resulting from the splitting of the $v_{3}$ mode of the dissolved sulfate ion. In this case, since only the vibrations with a dynamic dipole moment perpendicular to the surface are allowed by the surface selection rule, the band at 
<smiles>COS(OC)(OC)OC</smiles>

$v_{1}\left(A_{1}\right)$

$850-1000 \mathrm{~cm}^{-1}$ W

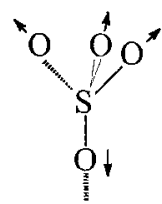

$$
v]\left(A_{1}\right)
$$$$
750-900 \mathrm{~cm}^{-1}
$$
W

$$
\mathrm{C}_{2 \mathrm{v}}
$$<smiles>CO[Si](C)(OC)OC</smiles>

$v_{3}\left(A_{1}\right)$

$1150-1250 \mathrm{~cm}^{-1}$ $\mathrm{S}$

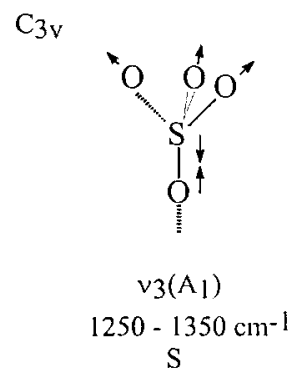

Figure 2. The surface selection rule allowed stretching vibration of the adsorbed $\mathrm{SO}_{4}{ }^{2-}$ ion under $\mathrm{C}_{2 \mathrm{v}}$ and $\mathrm{C}_{3 \mathrm{v}}$ symmetry (from Refs. 26, 27). W $=$ weak and $\mathrm{S}=$ strong (from IR intensities).

$1190 \mathrm{~cm}^{-1}$ is one $\mathrm{Al}$ mode. This mode is symmetric to the main symmetry axis and to the planes of a $C_{2 v}$ or $C_{3 v}$ symmetry. It is interesting to observe that the symmetric vibration resulting from the splitting of the $v_{3}$ mode gives a vibration with the band center shifted to higher wavenumbers than that of the free dissolved sulfate ions.

Usually, in the case of transition metal complexes where sulfate acts as a ligand, the splitting of the $v_{3}$ mode gives rise to the unsymmetrical vibration at higher wavenumbers and the symmetrical vibration at lower wavenumbers when compared to the position of the $v_{3}$ vibration of the free sulfate ion. In the case of the adsorption on the electrodes, however, the strong electric field of the electrochemical interface (see below), to which this displacement can be attributed, must not be ignored.

\section{The effect of the applied potential on adsorbed sulfate ions}

It has been well-documented that adsorbed ions and molecules at electrochemical interfaces are subjected to strong electrical fields $\left(>10^{6} \mathrm{~V} / \mathrm{cm}\right)$ and the surface coverage for adsorbed ions changes with the adsorption potential. In both cases, either due to the Stark effect or to lateral coupling, the center of the band shifts with the adsorption potential $^{22}$.

In Fig. 3 a set of spectra taken at different potentials are presented. It can be seen that the adsorption starts at about $0.6 \mathrm{~V}$ and increases up to $1.2 \mathrm{~V}$. This result contrasts with adsorbed sulfate on polycrystalline gold electrodes, where the adsorption starts at about $0.4 \mathrm{~V}^{17}$, but is essentially the same as that observed for $\mathrm{Au}(111)^{18}$. At 1.3 the adsorption of sulfate ions is strongly reduced to values below the

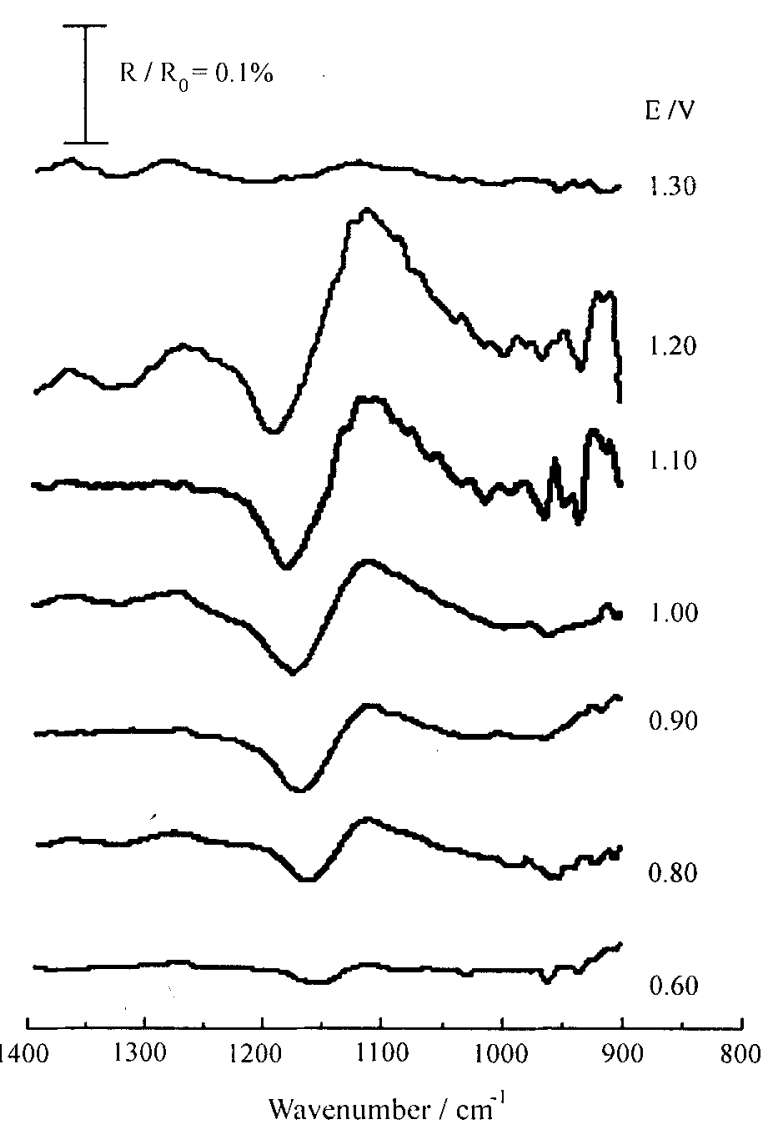

Figure 3. In situ FTIR spectra obtained with p-polarized radiation from a single crystal Au(100) siingle crystal electrode in $0.5 \mathrm{M} \mathrm{KF} / 0.69 \mathrm{M} \mathrm{HF}$ base solution $\left(\mathrm{pH}=2.8\right.$ ) containing $10^{-2} \mathrm{M} \mathrm{Na}_{2} \mathrm{SO}_{4}$. Sample potentials are as indicated. Reference potential $50 \mathrm{mV} v s$. Pd/ $\mathrm{H}_{2}$. Res.: $8 \mathrm{~cm}^{-1}$.

sensitivity of our measurements. The strong inhibition of the adsorption at $1.3 \mathrm{~V}$ is due to the competition with the formation of $\mathrm{AuOH}$, since the beginning of gold oxidation takes place.

It is interesting to observe that in the whole potential range only one band is observed ranging from 1160 to $1220 \mathrm{~cm}^{-1}$, due to the adsorbed ion. Also for $\mathrm{Au}(111)$ only one band above at the same wavenumber range $\left(1155-1220 \mathrm{~cm}^{-1}\right)$ is observed. Interestingly, adsorbed sulfate on polycrystalline gold at potentials below $0.7 \mathrm{~V}$ presents a second band at about $1100 \mathrm{~cm}^{-1}$, which has been interpreted as being due to the presence of co-adsorbed bisulfate ions.

The band shift with potential for the adsorbate band observed is plotted in Fig. 4. The slope of the band center wavenumber is $77 \mathrm{~cm}^{-1} / \mathrm{V}$. This result is very close to that observed for the adsorbed ions from a solution of similar composition on $\mathrm{Au}(111)\left(83 \mathrm{~cm}^{-1} / \mathrm{V}\right)$, but is much higher than the value observed for polycrystalline gold, where the observed slope is $44 \mathrm{~cm}^{-1} / \mathrm{V}$ for the same sulfate content in solution. 


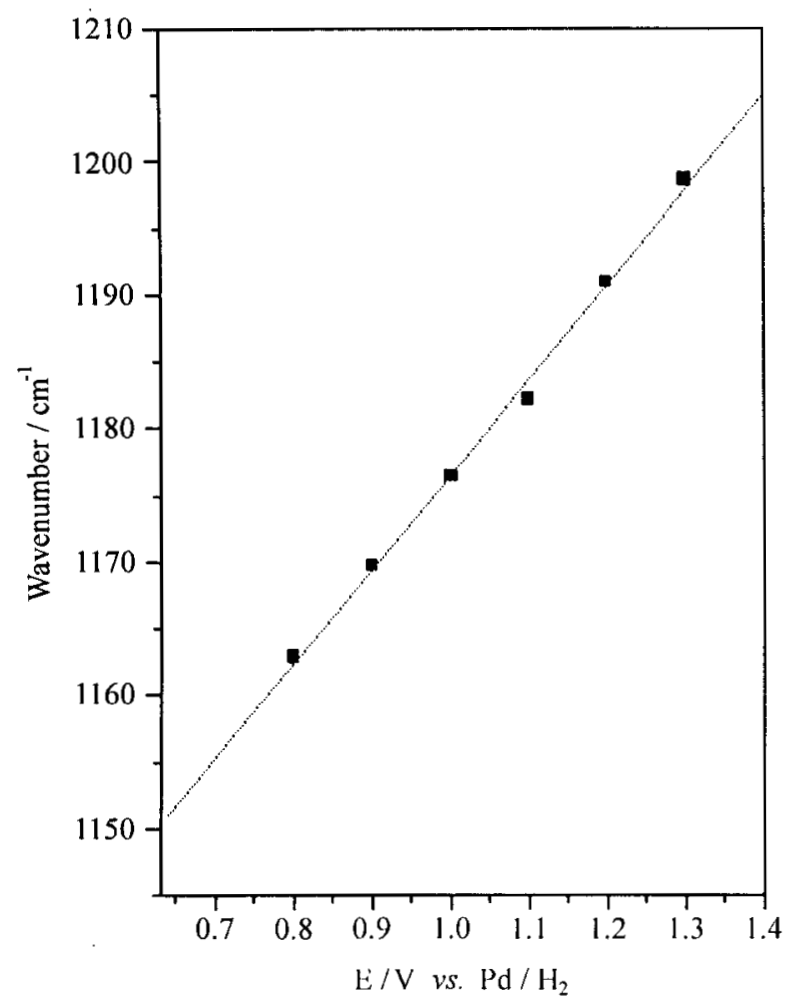

Figure 4. Band center frequency as a function of the applied potential for adsorbed sulfate on $\mathrm{Au}(100)$. Solution composition: $0.5 \mathrm{M} \mathrm{KF}, 0.69 \mathrm{M}$ $\mathrm{HF}, 10^{-2} \mathrm{M} \mathrm{Na}_{2} \mathrm{SO}_{4}(\mathrm{pH}=2.8)$.

The close agreement of these results with that observed for adsorbed sulfate on $\mathrm{Au}(111)^{18}$ means that the adsorption symmetry is probably the same in both cases. Since three-fold adsorption is not possible for the $\mathrm{Au}(100)$ surface, it seems reasonable to suppose that sulfate on gold electrodes may be adsorbed under two- or one-fold coordination.

\section{The adsorption of sulfate species in strongly acid solutions}

It has been reported that bisulfate ions from very acidic solutions are deprotonated when adsorbed on positively polarized $\mathrm{Pt}(111)^{15}$ and $\mathrm{Au}(111)^{18}$ electrodes, which means that in the adsorbed state the bisulfate ions increase the base character, thus causing proton loss. The suggested mechanism for the enhancement of the base character is a partial charge transfer, proposed by Orts et al. ${ }^{28}$, based on electrochemical experiments.

To verify whether bisulfate can be adsorbed at $\mathrm{Au}(100)$ surfaces as in the case of polycrystalline gold electrodes ${ }^{17}$, spectra of the $\mathrm{Au}(100)$ surface were obtained in very concentrated HF solutions containing bisulfate ions. The results are presented in Fig. 5 for different adsorption potentials.

Two bands above $1000 \mathrm{~cm}^{-1}$ can be observed for all spectra, but the relative intensity of the two bands changes with the applied potential. The band at $1200 \mathrm{~cm}^{-1}$ increases,

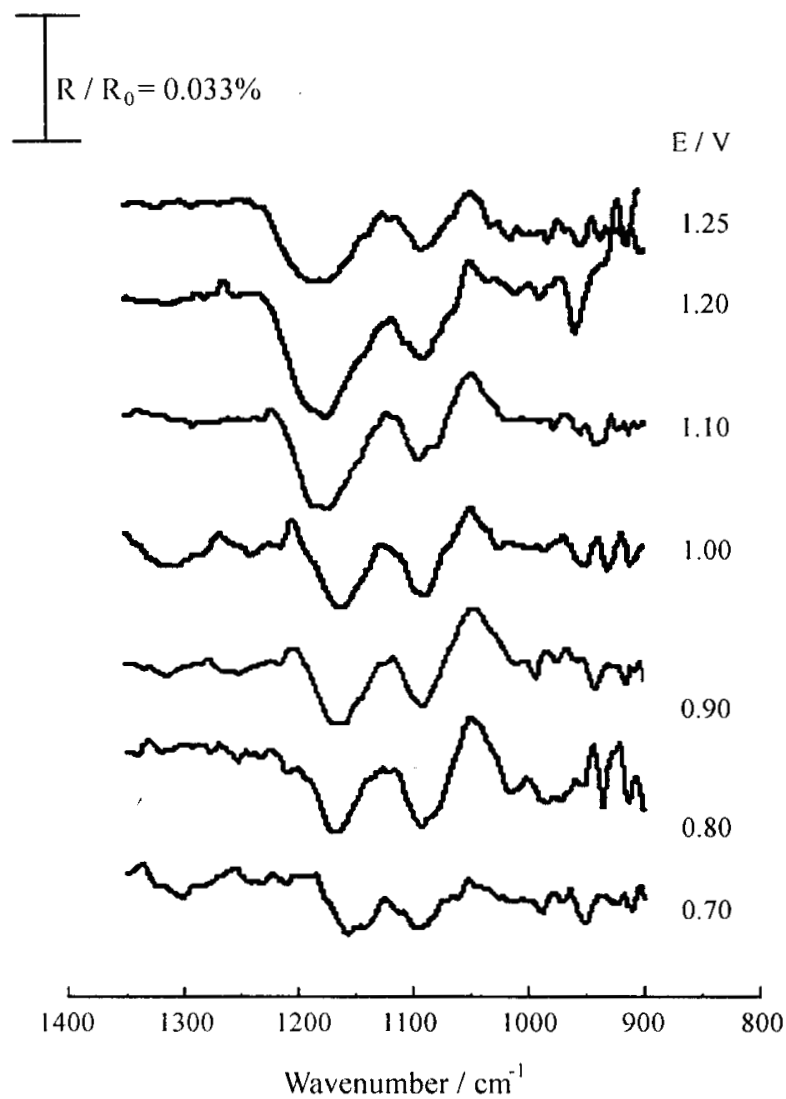

Figure 5. In situ FTIR spectra obtained with p-polarized radiation from a single crystal $\mathrm{Au}(100)$ single crystal electrode in $7.3 \mathrm{M} \mathrm{HF}$ base solution $\left(\mathrm{pH}=0.23\right.$ ) containing $10^{-2} \mathrm{M} \mathrm{Na}_{2} \mathrm{SO}_{4}$. Sample potentials as indicated. Reference potential $50 \mathrm{mV}$ vs. $\mathrm{Pd} / \mathrm{H}_{2}$. Res.: $8 \mathrm{~cm}^{-1}$.

while the band at $1100 \mathrm{~cm}^{-1}$ decreases in intensity. The band at $1100 \mathrm{~cm}^{-1}$ is typical for adsorbed bisulfate, since adsorbed sulfate presents only the band located at 1150$1220 \mathrm{~cm}^{-1}$.

Bisulfate ions in solution present the doubly degenerated mode (E) at $1200 \mathrm{~cm}^{-1}$, and a symmetric mode at $1050 \mathrm{~cm}^{-1}$. When adsorbed, either through one or two oxygen atoms, the resulting symmetry is $\mathrm{C}_{\mathrm{s}}$. In this case, the doubly degenerated mode splits into two bands. Therefore, for Cs symmetry, four stretching vibrations are expected, Three A' and one A". The A" has a dipole moment perpendicular to the symmetry plane ( $\mathrm{z}$ direction) and therefore lies parellel to the surface and is forbiden by the surface selection rule. From the $A^{\prime}$ two have a dipole moment in the $\mathrm{y}$ direction and one in the $\mathrm{x}$ direction. Therefore, two modes are perpendicular to the surface (the $y$ direction) and are allowed by the surface selection rule.

The schematic representation of adsorbed $\mathrm{HSO}_{4}{ }^{-}$ions under one and two oxygen atoms is depicted in Fig. 6. Only the $v_{1}\left(A^{\prime}\right)$ and one of the $v_{3}$ split bands are allowed for the adsorbate. The difference between one-fold and two-fold coordinations is the allowed band arising from the splitting 
<smiles>COS(O)(O)OC</smiles><smiles>COS(O)(O)OC</smiles><smiles>CO[SH](=O)(O)OC</smiles><smiles>COS(=O)(O)(O)OC</smiles>

Figure 6. Schematic structures of adsorbed $\mathrm{HSO}_{4}{ }^{-}$ions through one and two oxygen atoms and the corresponding allowed stretching vibrations.

of the $v_{3}$ mode. It is likely that there is some small difference in the band center wavenumber due to the difference in coordination. In the case of two-fold coordination, the contribution of a SO and $\mathrm{SOH}$ bending to the mode may be larger than in the case of single coordination. It is very difficult, however, to assign a specific vibration to the band without a detailed normal coordinate analysis, which is not trivial in the case of multi-atom adsorbates on transition metal surfaces. It is very likely that the predominant coordination is through two oxygen atoms, since the charge over the oxygen atoms is uniformly distributed for the case of bisulfate ions in solution and there would be no apparent reason for the bisulfate to be adsorbed by only one oxygen atom. The double coordination, instead of a three-fold coordination is due to the fact that the geometry of the surface atoms does not allow a three-fold coordination for the case of sulfate and bisulfate ions.

Therefore, both adsorbed sulfate and bisulfate present only one allowed band above $1000 \mathrm{~cm}^{-1}$. The two bands in the spectra of Fig. 5 shows that sulfate and bisulfate are therefore co-adsorbed in the whole potential range, but the relative amount of each species changes with the applied potential. The predominance of the $1090 \mathrm{~cm}^{-1}$ band at low potentials, and of the $1200 \mathrm{~cm}^{-1}$ band at higher potentials, reveals that the amount of positive charge at the surface favors the increase of adsorbed sulfate ions. It is interesting to note the differences between $\mathrm{Au}(100)$ and $\mathrm{Au}(111)$ : as reported by Edens et al. ${ }^{18}$, in very acid solutions only sulfate ions are adsorbed on $\mathrm{Au}(111)$ even at low potentials, while adsorbed bisulfate can be easily detected on $\mathrm{Au}(100)$ in very acidic solutions.

\section{The adsorption of nitrate ions}

Free nitrate ions in solution belong to the $D_{3 h}$ point group and present two stretching vibrations above 900 $\mathrm{cm}^{-1}$. The totally symmetric vibrations at $1043 \mathrm{~cm}^{-1}$ are IR forbidden. However, the dissolved nitrate in aqueous solution presents a distorted $D_{3 h}$ symmetry, since the totally symmetric mode can be seen in a transmission spectrum as a very weak band, and the two-fold degenerated mode at $1396 \mathrm{~cm}^{-1}$ is slightly split into two bands, as can be observed in the spectrum of Fig. 7. The interaction of nitrate ions with the solvent water may be strong enough to produce symmetry distortion.

The spectra for adsorbed nitrate ions on $\mathrm{Au}(100)$ at three different potentials in acidic solution containing HF as the supporting electrolyte can be seen in Fig. 8. Two bands can be clearly distinguished, a very weak one at $1030 \mathrm{~cm}^{-1}$ and one strong band at $1440-1450 \mathrm{~cm}^{-1}$. These two modes can be assigned to the $v_{1}$ mode and to the split $v_{3}$ mode of the nitrate ions.

Nitrate ions adsorbed through the oxygen atoms belong to the $\dot{\mathrm{C}}_{2 v}$ point group, whether if adsorbed by one or two oxygen atoms. In both cases, only two stretching modes are allowed by the surface selection rule. As stressed above, only two bands are observed in the spectra of Fig. 8, showing that one of the bands in the doublet presented in Fig. 7 has a dipole moment parallel to the surface, and is forbidden by the surface selection rule.

More information about the coordination of nitrate ions to $\mathrm{Au}(100)$ electrodes can be obtained by comparing the band position of the adsorbed nitrate with nitrate coordination compounds. The band position for nitrate coordination compounds can be found in Nakamoto ${ }^{27}$. Accordingly, one-fold coordination gives rise to two symmetric vibra-

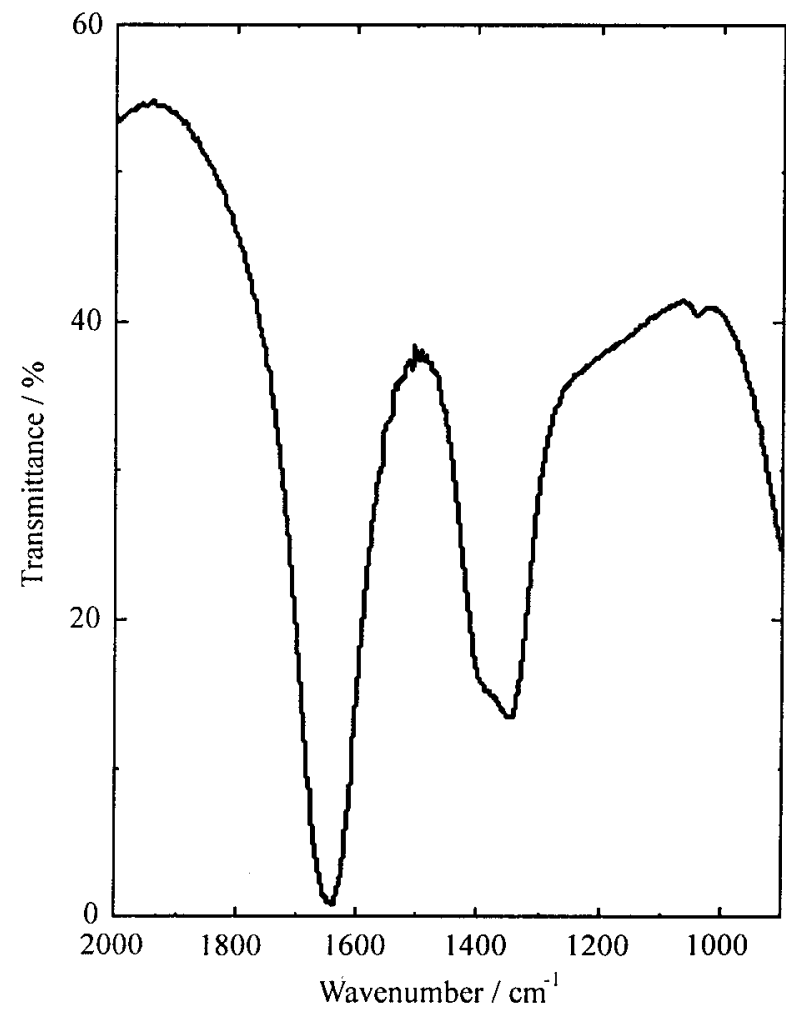

Figure 7. Transmittance spectra of $1 \mathrm{M} \mathrm{HNO}_{3}$ aqueous solution. Res: $4 \mathrm{~cm}^{-1}$. 


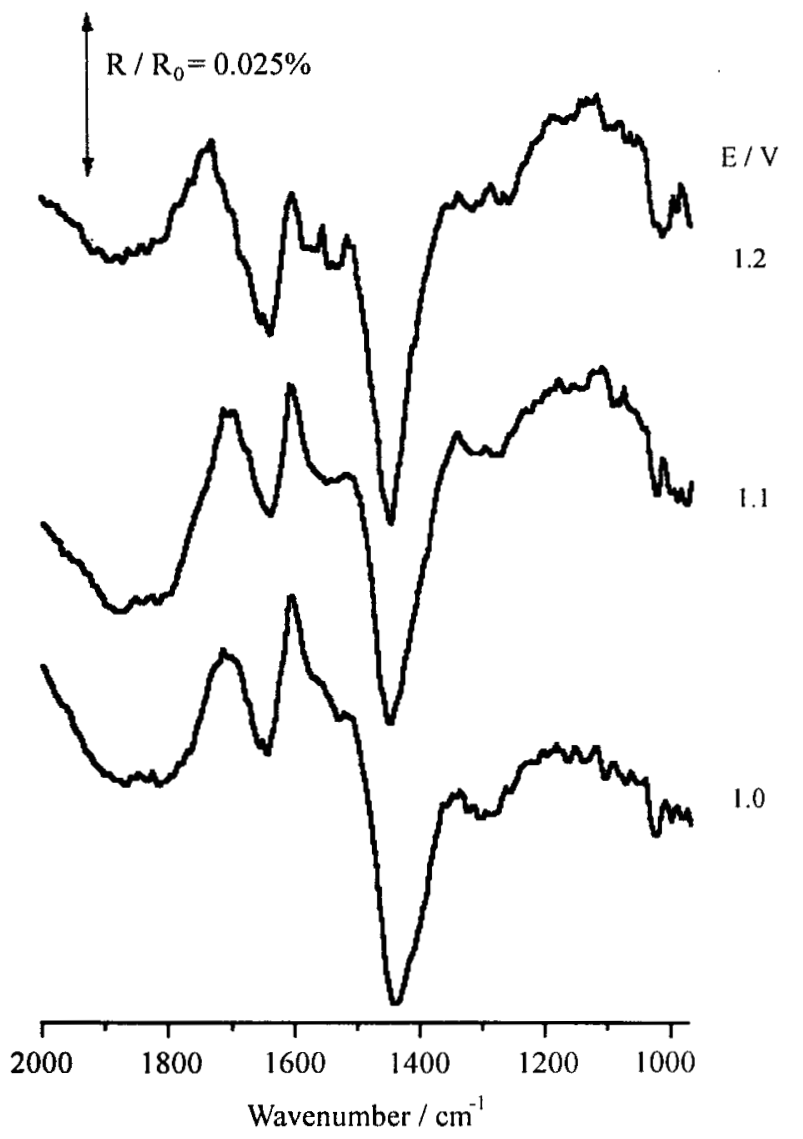

Figure 8. Spectra obtained with p-polarized radiation of the $\mathrm{Au}(100)$ electrode in a solution of $1 \mathrm{M} \mathrm{HF}+0.05 \mathrm{M} \mathrm{HNO}_{3}$ at different electrode potentials, as indicated. Reference potential $0.05 \mathrm{~V} v \mathrm{~s}$. $\mathrm{Pd} / \mathrm{H}_{2}$. Res: $8 \mathrm{~cm}^{-1}$.

tions with bands at 1008 and $1305 \mathrm{~cm}^{-1}$. Chelating bidentate nitrate complexes also give rise to two symmetric stretching vibrations with bands at $1025 \mathrm{~cm}^{-1}$ and $1476 \mathrm{~cm}^{-1}$. Direct comparison with the present results (1440-1450 and $1030 \mathrm{~cm}^{-1}$ ) suggests that the most likely structure for adsorbed nitrate on $\mathrm{Au}(100)$ is the bridge form. Similar structures have been observed for nitrate adsorbed on polycrystalline gold electrodes ${ }^{23}$. The only difference observed between $\mathrm{Au}(100)$ and polycrystalline gold electrodes $^{23}$ is that the totally symmetric stretching vibration is not observed in the case of polycrystalline gold. Moreover, at polycrystalline gold electrodes the reduction of nitrate ions to nitrite ions has been observed ${ }^{23}$.

It is interesting to note that the $1396 \mathrm{~cm}^{-1}$ band has shifted to $1440-1450 \mathrm{~cm}^{-1}$, thus to higher wavenumbers, while the band originating from the totally symmetric vibration slightly shifts to lower wavenumbers. This is also the case for coordination compounds (see discussion above), and can be rationalized taking into account the changes in bond order upon coordination.

It is well-documented that the bond between the coordinated oxygen and the nitrogen atom increases in lenght, meaning a decrease in bond order. The bond between the

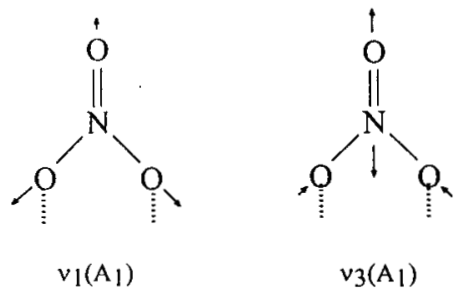

Figure 9. Schematic of the most probable structure of adsorbed $\mathrm{NO}_{3}{ }^{-}$ions on $\mathrm{Au}(100)$ and the corresponding allowed stretching vibrations $\left(v_{1}=\right.$ $1043 \mathrm{~cm}^{-1}$ and $\left.v_{3}=1440-1450 \mathrm{~cm}^{-1}\right)$.

nitrogen and the non-coordinated oxygen shortens. Accordingly, the bond between the non-coordinated oxygen and nitrogen has been represented as a double bond ${ }^{27}$. In this case, the higher wavenumber mode is predominantly the $\mathrm{N}=\mathrm{O}$ group vibration of the non-coordinated bond and the stretching vibrations are thus blue shifted. On the other hand, the lower wavenumber mode is dominated by the coordinated $\mathrm{NO}_{2}$ group, thus producing a decrease in the vibration energy, since the bond is weakened. Parallel to this interpretation, the high electrical field at the interface also plays an important role in the band displacment. The higher wavenumber mode has the dominating vibration with oscillations of the oxygen atoms against the electrical field of the double layer, while the low wavenumber mode of the oxygen displacement occurs in the same direction of the field and partially against the field and in the direction of the field. In this case, the electrical field acts differently at both oscillations (see Fig. 9).

In the case of the mode originating from the totally symmetric vibration, the vibrations correspond mainly to the displacement of two groups, the non-coordinated $\mathrm{N}=\mathrm{O}$ and the coordinated $\mathrm{NO}_{2}$ in the opposite direction and in this case the effect of the electrical field is somewhat compensated for the total band shift, which could justify the small displacement to lower wavenumbers for the mode originating from the totally symmetric vibration.

\section{Concluding Remarks}

Vibrational spectroscopy was used to study the adsorption of sulfate, bisulfate, and nitrate ions on a $\mathrm{Au}(100)$ electrode.

Adsorbed sulfate presents one active potential dependent band at $1150-1220 \mathrm{~cm}^{-1}$ and one bisulfate band at 1090 $\mathrm{cm}^{-1}$. Bisulfate and sulfate are co-adsorbed at very concentrated HF solutions, but the increase in positive potentials leads to the deprotonation of part of the bisulfate ions.

Nitrate ions are mostly bridge coordinated to the $\mathrm{Au}(100)$ surface under $C_{2 v}$ symmetry.

\section{Acknowledgments}

The authors are indebted to FAPESP, CNPq and FINEP for financial support for this work. P. Beatrice and J.B. 
Ferreira are also gratefully acknowledged for technical support.

\section{References}

1. Hoffimann, F.M. Surf. Sci. Rep. 1983, 3, 107.

2.Chabal, Y.J. Surf. Sci. Rep. 1988, 8, 211.

3. Hollins, P.; Pitchard, J. Prog. Surf. Sci. 1985, 19(4), 275.

4. Wilke, T.; Gao, X.; Takoudis, C.G.; Weaver, M.J. J. Catalysis 1991, 130, 62.

5.Bewick, A.; Kunimatsu, K.; Pons, S. Electrochim. Acta 1980, 25, 465.

6. Pons, S.; Davidson, T.; Bewick, A. J. Am. Chem. Soc. 1983, 105, 1892.

7. Bae, I.T.; Xiang, X.; Yeager, E.B. Anal. Chem. 1989, 61,1164 .

8. Bae, I.T.; Scherson, D.; Yeager, E.B. Anal. Chem. $1990,62,45$.

9. Iwasita, T.; Nart, F.C. J. Electroanal. Chem. 1990, $295,215$.

10. Iwasita, T.; Nart, F.C.; Polligkeit, H.; Ber. Bunsenges. Phys. Chem. 1991, 95, 638.

11. Corrigan, D.S.; Weaver, M.J. J. Electroanal. Chem. 1988, 239, 55.

12. Nart, F.C.; Iwasita, T. J. Electroanal. Chem. 1991, 308, 277.

13. Nart, F.C.; Iwasita, T. J. Electroanal. Chem. 1992, $322,289$.

14. Faguy, P.W.; Markovic, N.; Adzic, R.R.; Fierro, C.A.; Yeager, E.B. J. Electroanal. Chem. 1990, 391, 280.
15. Nart, F.C.; Iwasita, T.; Weber, M. Electrochim. Acta 1994, 39, 961 .

16. Nart, F.C.; Iwasita, T.; Weber, M. Electrochim. Acta 1994, 39, 2093.

17. Weber, M.; Nart, F.C. Langmuir 1996, 12, 1895.

18. Edens, G.J.; Gao, X.; Weaver, M.J. J. Electroanal. Chem. 1994, 375, 357.

19. Habbib, M.A.; Bockris, J.O'M. J. Electrochem. Soc. 1985, 132, 108.

20. Paulissen, V.B.; Korzeniewski, C. J. Electroanal. Chem. 1990, 290, 181.

21. Nart, F.C.; Iwasita, T. Electrochim. Acta 1992, 37, 385.

22. Weber, M.; Nart, F.C. Electrochim. Acta 1996, 4I, 653.

23. Cunha, M.C.P.M.; Weber, M.; Nart, F.C. J. Electroanal. Chem., 1996, 414, 163. In press.

24. Horanyi, G.; Rizmayer, E.M. J. Electroanal. Chem. 1980, 25, 347.

25. Kolb, D.M.; Schneider, J. Electrochim. Acta 1986, 31, 429.

26. Burke, M.L.; Madix, R.J. J. Phys. Chem. 1988, 92, 1974.

27. Nakamoto, K. Infrared and Raman Spectra of Inorganic and Coordination Compounds, Wiley, New York (1978).

28. Orts, J.M.; Gómez, R.; Feliu, J.M.; Aldaz, A.; Clavilier, J. Electrochim. Acta 1994, 39, 1519.

FAPESP helped in mecting the publication costs of this article 